http://jmscr.igmpublication.org/home/ ISSN (e)-2347-176x ISSN (p) 2455-0450

crossref DOI: https://dx.doi.org/10.18535/jmscr/v8i2.82

\title{
3 Arm comparisons to evaluate the role of concurrent chemoradiation in locally advanced squamous cell carcinoma of head \& neck region
}

\author{
Authors \\ Tabassum Samani $^{1 *}$, Alvin Anto ${ }^{2}$, A K Arya ${ }^{3}$ \\ ${ }^{1}$ Assistant Professor, Department of Radiotherapy, S.N. Medical College \& hospital, Agra, Uttar Pradesh, \\ INDIA \\ ${ }^{2}$ Junior Resident, Department of Radiotherapy, S.N. Medical College \& hospital, Agra, Uttar Pradesh, \\ INDIA \\ ${ }^{3}$ Prof \& Head, Department of Radiotherapy, S.N. Medical College \& hospital, Agra, Uttar Pradesh, INDIA \\ *Corresponding Author \\ Dr Tabassum Samani \\ Assistant Professor, Department of Radiotherapy, S.N. Medical College \& hospital, Agra, Uttar Pradesh, \\ INDIA
}

\begin{abstract}
Background: In locally advanced squamous cell carcinoma of head and neck regionthe most widely used drug in concurrent chemoradiation is cisplatin but the optimal regimen of cisplatin is still not defined. The aim of this study was to determine the efficacy of CCRT with weekly cisplatin vs 3 weekly cisplatin and 5 fluorouracil and to compare it with conventional radiotherapy only treatment. We also evaluated the toxicity of the 3 arms.

Material and Method: Outcome data of 60 patients of histologically proven squamous cell carcinoma of head and neck treated between 2007-2010 was analysed. 20 patients had received only conventional RT; 20 patients had received conventional $R T$ along with weekly cisplatin and 20 patients had received conventional RT along with cisplatin \& 5-FU on D1-D4 \&D22-25 of RT.

Results: At 5 years overall survival was $25 \%$ in the RT only arm, 50\% in the weekly cisplatin arm and $35 \%$ in the 3 weekly cisplatin and 5-FU arm. The DFS was 20\%, 40\% \&25\% respectively in the 3 arms.

Conclusion: Patients treated with weekly cisplatin CCRT had a higher 5 year OS and DFS as compared to those treated with 3 weekly cisplatin \& 5FU CCRT or RT alone.
\end{abstract}

\section{Introduction}

Head and neck cancers are a heterogenous group of cancers and worldwide approximately 600,000 patients are afflicted. ${ }^{1}$ In India over 200,000 new cases of Head \& Neck cancers and over 100,000 deaths occur each year. ${ }^{2}$ Majority of the patients are in the 50-70 years age group. ${ }^{1}$ Traditionally surgery and radiotherapy either alone for early stage disease or in combination for locoregionally advanced disease had been considered curative for $\mathrm{H} \& \mathrm{~N}$ cancers. ${ }^{3,4}$ Optimal treatment for locally advanced head \& neck cancer remains a challenge and concurrent chemoradiation is now considered the standard of care for nonsurgical treatment of these patients. ${ }^{5-8}$ 
A meta-analysis of $>17,346$ patients of 93 trials conducted from 1965-2000 (meta-analysis of chemotherapy on Head and Neck cancer [MACH$\mathrm{NC}$ ) demonstrated that the use of radiotherapy and concurrent chemotherapy (CCRT) resulted in a $19 \%$ reduction in the risk of death and an overall $6.5 \%$ improvement in the 5 year survival compared to treatment with RT alone. ${ }^{9}$ The most widely used chemotherapy drug is cisplatin but the optimal regimen of cisplatin is still not defined. The most widely used concurrent chemoradiation schedule uses high dose bolus cisplatin $100 \mathrm{mg} / \mathrm{m}^{2}$ every 3 weeks in combination with standard radiotherapy. ${ }^{9-13}$ Cisplatin has also been used concurrently with radiation in other schedules - low dose daily, few days per week, or weekly schedule. ${ }^{14-17}$

There exists considerable difference in choosing the optimal chemoradiation schedule due to heterogeneity of study designs and different ways of combining CT and RT. This retrospective study attempts to analyse patients treated with two different regimens of cisplatin based CCRT and to compare their results with RT alone. The aim was to see OS and DFS at 5 year. We also analysed the acute and late toxicities in the 3 arms.

\section{Material and Methods \\ Patients}

Patients with head and neck cancer who were treated with only RT, RT with weekly cisplatin and RT with 3 weekly cisplatin and 5-FU from December 2007to December 2010 were retrospectively identified from our department data base. 20 patients were identified in each of the 3 arms. Inclusion criteria were histologically proven squamous cell carcinoma of, locally advanced (stage III \& IV) where surgery not feasible / refused, no previous oncological therapy other than biopsy, KPS 60-100, no significant comorbidity that would preclude the use of CT and RT, age greater than 20 years, normal hematological, renal and liver function tests and no previous cancer within last 5 years or a second primary. Exclusion criteria were patients with distant metastasis, recurrent tumors, second primary neoplasm, paranasal sinusand nasopharyngeal cancer.

\section{Treatment}

Patients in arm A received only conventional RT. Patients in arm B received Inj cisplatin $40 \mathrm{mg} / \mathrm{m}^{2}$ weekly along with conventional RT. Patients in arm $\mathrm{C}$ received Inj cisplatin $20 \mathrm{mg} / \mathrm{m}^{2} \&$ Inj 5-FU $1 \mathrm{gm} / \mathrm{m}^{2}$ on days 1-4and days 22-25 of conventional RT. The total dose of RT was $60-70$ Gy at 2 Gyper fraction, 5 fractions/week in all the 3 arms. Most of the patients were treated with $\mathrm{B} / \mathrm{L}$ opposing portals and a few with 3 field technique (B/L opposing portals for primary and upper neck and a low anterior neck field matched to the upper field). Field reduction was done at $44 \mathrm{~Gy}$ to spare the spinal cord. All patients were treated with Cobalt-60 machine.

\section{Assessment of Toxicity and Response}

All the patients were monitored weekly to evaluate the development of acute toxicities like nausea, vomiting, mucositis, skin rash and neutropenia. Blood counts, RFT and LFT were performed weekly during RT. Treatment toxicities were graded according to the RTOG guidelines. Patients whose performance status, LFT, RFT or $\mathrm{CBC}$ deteriorated during RT were considered unfit for CT. In these patients that particular cycle of CT was omitted and no dose reductions were planned.

Primary and nodal response was assessed clinically every week during treatment and after one month of completion of treatment. Thereafter patients were followed up monthly for the first year, once in 3 months in the second year, once in 6 months in the third to fifth year and then annually. In follow up, detailed clinical examination was done to see the result of the treatment at the disease site and lymph node region, toxicities and detection of any distant metastasis. Treatment response was assessed by the RECIST criteria. If there was any suspicion of recurrence, patient was sent for evaluation and 
biopsy. Patients who had completed the planned treatment but were not coming for follow up were contacted telephonically.

\section{Data Analysis}

Analysis was performed using SPSS software. The study was approved by our institutional ethics committee and all the patients provided informed consent.

\section{Results}

\section{Patient Characteristics}

Table 1 depicts the characteristics of the patients. Overall $80 \%$ of the patients were males and the median age at presentation was 57 years in arm A, 56 years in arm B and 55.5 years in arm C, with a range from 35-72 years. Overall the most common primary site was oropharynx (31.6\%) followed by larynx $(30 \%)$ hypopharynx $(21.6 \%)$ and oral cavity $(16.67 \%)$ In arm A, $12(60 \%)$ patients were in stage III \& 8(40\%) in stage IV. In arm B $9(45 \%)$ were in stage III and $11(55 \%)$ in stage IV where as in arm C 10pts were in stage III \& IV each $(50 \%)$.

Analysis of Overall Tumor Response and Survival at 5 Years

All patients completed the planned treatment. Patients were followed for 30-66 months with a median follow up of 42 months. At the first follow up, after one month of completion of treatment, complete response was seen in 12 patients $(60 \%)$ in arm A, 17(85\%) in arm B and 15(75\%) in arm C. Partial response was seen in 6 patients $(30 \%)$ in arm A, 3(15\%) in arm B and 5(25\%) in arm C. Stable disease was seen in 2 patients $(10 \%)$ in arm A. As a measure of efficacy of treatment the analysis was limited to first failures only. Data was analysed till June 2013. At that time, the projected overall survival at 5 years was $25 \%$ in Arm A, 50\% in Arm B and 35\% in Arm C. The projected DFS at 5 years was $20 \%$ in arm A, $40 \%$ in arm B and $25 \%$ in arm C.

\section{Toxicity Analysis}

Acute toxicity: Median time of onset of symptoms of acute toxicities was 18 days in arm A, 16 days in arm B and 12 days in arm C. Most of the patients in arm A suffered Grade I/II toxicities where as in CCRT arms Grade III/IV toxicities were more prevalent. Majority of the patients in arm A experienced Grade I/II skin toxicity. In arm B , Grade III and IV skin toxicity was seen in $50 \%$ \& $20 \%$ of the patients. Patients in arm $\mathrm{C}$ experienced more severe skin toxicity with $45 \%$ Grade III and $30 \%$ Grade IV skin reactions. Grade III mucositis was $60 \%$ in arm B $\$ 50 \%$ in arm $\mathrm{C}$ whereas Grade IV mucositis was more common in arm $\mathrm{C}(35 \%)$ as compared to arm B (15\%). Majority of the patients in arm A experienced Grade I \& II mucosal toxicity. Nausea and vomiting was mild to moderate in arm A Grade II vomiting was $60 \%$ in arm B \& $50 \%$ in arm $\mathrm{C}$ whereas Grade III vomiting was seen in $20 \%$ of patients in arm B and 35\% in arm C. Dysphagia was mostly Grade I/II in arm A. Both the arms B and $\mathrm{C}$ experienced Grade II dysphagia in $50 \%$ patients. Grade III dysphagia was higher in arm C as compared to arm B (45\% vs 30\%). Neutropenia was experienced by 2 patients $(10 \%)$ in arm B and one patient (5\%) in arm C.High incidence of mucositis and dysphagia in the concurrent arms led to a more frequent use of NG tube feeding in the CCRT arms as compared to the RT only arm. NG tube insertion was done in 11 patients (55\%) in arm B and 14 patients $(70 \%)$ in arm $\mathrm{C}$ as compared to only one patient $(5 \%)$ in arm A.

Late Toxicity: The most prominent late toxicity seen at the time of analysis was xerostomia. Out of the 5 patients alive in arm A, 3 had Grade I\& 1 had II toxicity. Of the 10 patients alive in arm B, 6 had Grade I and 4 had II toxicity. Out of the 7 patients alive in arm C , 4 had Grade I \& 3 had II toxicity. Subcutaneous fibroses was seen in 2 patients in arm A, 4 patients in arm B and 3 patients in arm C. Trismus was present in 1 patient in arm A and 2 in arm B and $\mathrm{C}$ each. Significant hearing lost was seen in 3 patients in arm B and 2 patients in arm C. Persistent dysphagia was seen in 2 patients in arms B and C each. 
Table-1 Patient Characteristics

\begin{tabular}{|l|c|c|c|c|c|c|c|c|c|}
\hline \multirow{2}{*}{ S. No. } & & \multicolumn{2}{|c|}{ RT only } & \multicolumn{2}{c|}{ RT+ Wkly Cisplatin } & \multicolumn{2}{c|}{ RT+3 wkly CDD+ 5-FU } & \multicolumn{2}{c|}{ Total } \\
\cline { 3 - 10 } & & No. & $\%$ & No. & $\%$ & No. & $\%$ & No. & $\%$ \\
\hline 1 & Number of patients & 20 & & 20 & & 20 & & 60 & \\
\hline 2 & Male:female & $16: 4$ & $80 / 20$ & $15: 5$ & $75 / 25$ & $17: 3$ & $85 / 15$ & $48 / 12$ & $80 / 20$ \\
\hline 3 & Median age (years) & 57 & & 56 & & 55 & & & \\
\hline 4 & Disease location & & & & & & & & \\
\hline & Oropharynx & 6 & 30 & 6 & 30 & 7 & 35 & 19 & 31.6 \\
\hline & Larynx & 7 & 35 & 6 & 30 & 5 & 25 & 18 & 30 \\
\hline & Hypopharynx & 4 & 20 & 4 & 20 & 5 & 25 & 13 & 21.6 \\
\hline & Oral cavity & 3 & 15 & 4 & 20 & 3 & 15 & 10 & 16.7 \\
\hline 5 & Stage & & & & & & & & \\
\hline & III & 12 & 60 & 9 & 45 & 10 & 50 & 29 & 48.3 \\
\hline & IV & 8 & 40 & 11 & 55 & 10 & 50 & 31 & 51.7 \\
\hline
\end{tabular}

Table - 2 Results

\begin{tabular}{|c|c|c|c|c|c|c|c|}
\hline \multirow[t]{2}{*}{$\begin{array}{l}\text { S. } \\
\text { No. }\end{array}$} & & \multicolumn{2}{|c|}{$\begin{array}{l}\text { RT } \\
\text { only }\end{array}$} & \multicolumn{2}{|c|}{$\begin{array}{c}\text { RT + Weekly } \\
\text { Cisplatin }\end{array}$} & \multicolumn{2}{|c|}{$\begin{array}{l}\text { RT + } 3 \text { Weekly } \\
\text { Cisplatin }+5 \text { FU }\end{array}$} \\
\hline & & No. & $\%$ & No. & $\%$ & No. & $\%$ \\
\hline 1 & CR & 12 & 60 & 17 & 85 & 15 & 75 \\
\hline 2 & PR & 6 & 30 & 3 & 15 & 5 & 25 \\
\hline 3 & SD & 2 & 10 & 0 & 0 & 0 & 0 \\
\hline 4 & Median duration of Followup & & & & & & \\
\hline 5 & OSat 5 years & 5 & 25 & 10 & 50 & 7 & 35 \\
\hline \multirow[t]{2}{*}{6} & DFS at 5 year & 4 & 20 & 8 & 40 & 5 & 25 \\
\hline & Acute toxicities & & & & & & \\
\hline \multirow[t]{5}{*}{7} & Mucositis Grade & & & & & & \\
\hline & I & 10 & 50 & 0 & 0 & 0 & 0 \\
\hline & II & 8 & 40 & 5 & 25 & 3 & 15 \\
\hline & III & 2 & 10 & 12 & 60 & 10 & 50 \\
\hline & IV & 0 & 0 & 3 & 15 & 7 & 35 \\
\hline \multirow[t]{5}{*}{8} & Dermatitis & & & & & & \\
\hline & I & 12 & 60 & 2 & 10 & 0 & 0 \\
\hline & II & 8 & 40 & 4 & 20 & 5 & 25 \\
\hline & III & 0 & 0 & 10 & 50 & 9 & 45 \\
\hline & IV & 0 & 0 & 4 & 20 & 6 & 30 \\
\hline \multirow[t]{5}{*}{9} & Vomiting & & & & & & \\
\hline & 0 & 10 & 50 & 0 & 0 & 0 & 0 \\
\hline & I & 6 & 30 & 4 & 20 & 3 & 15 \\
\hline & II & 4 & 20 & 12 & 60 & 10 & 50 \\
\hline & III & 0 & 0 & 4 & 20 & 7 & 35 \\
\hline \multirow[t]{4}{*}{10} & Dysphagia & & & & & & \\
\hline & $\mathrm{I}$ & 10 & 50 & 4 & 20 & 1 & 5 \\
\hline & II & 9 & 45 & 10 & 50 & 10 & 50 \\
\hline & III & 1 & 5 & 6 & 30 & 9 & 45 \\
\hline \multirow[t]{2}{*}{11} & Neutropenia & 0 & & 2 & 10 & 1 & 5 \\
\hline & Late toxicity & & & & & & \\
\hline \multirow[t]{4}{*}{12} & Salivary gland & & & & & & \\
\hline & 0 & 1 & & 0 & & 0 & \\
\hline & I & 3 & & 6 & & 4 & \\
\hline & II & 1 & & 4 & & 3 & \\
\hline \multirow[t]{3}{*}{13} & Subcutaneous fibrosis & & & & & & \\
\hline & Present & 2 & & 4 & & 3 & \\
\hline & Absent & 3 & & 6 & & 4 & \\
\hline 14 & Trismus & 1 & & 2 & & 2 & \\
\hline 15 & Hearing loss & 0 & & 3 & & 2 & \\
\hline 16 & Dysphagia & 0 & & 2 & & 2 & \\
\hline
\end{tabular}



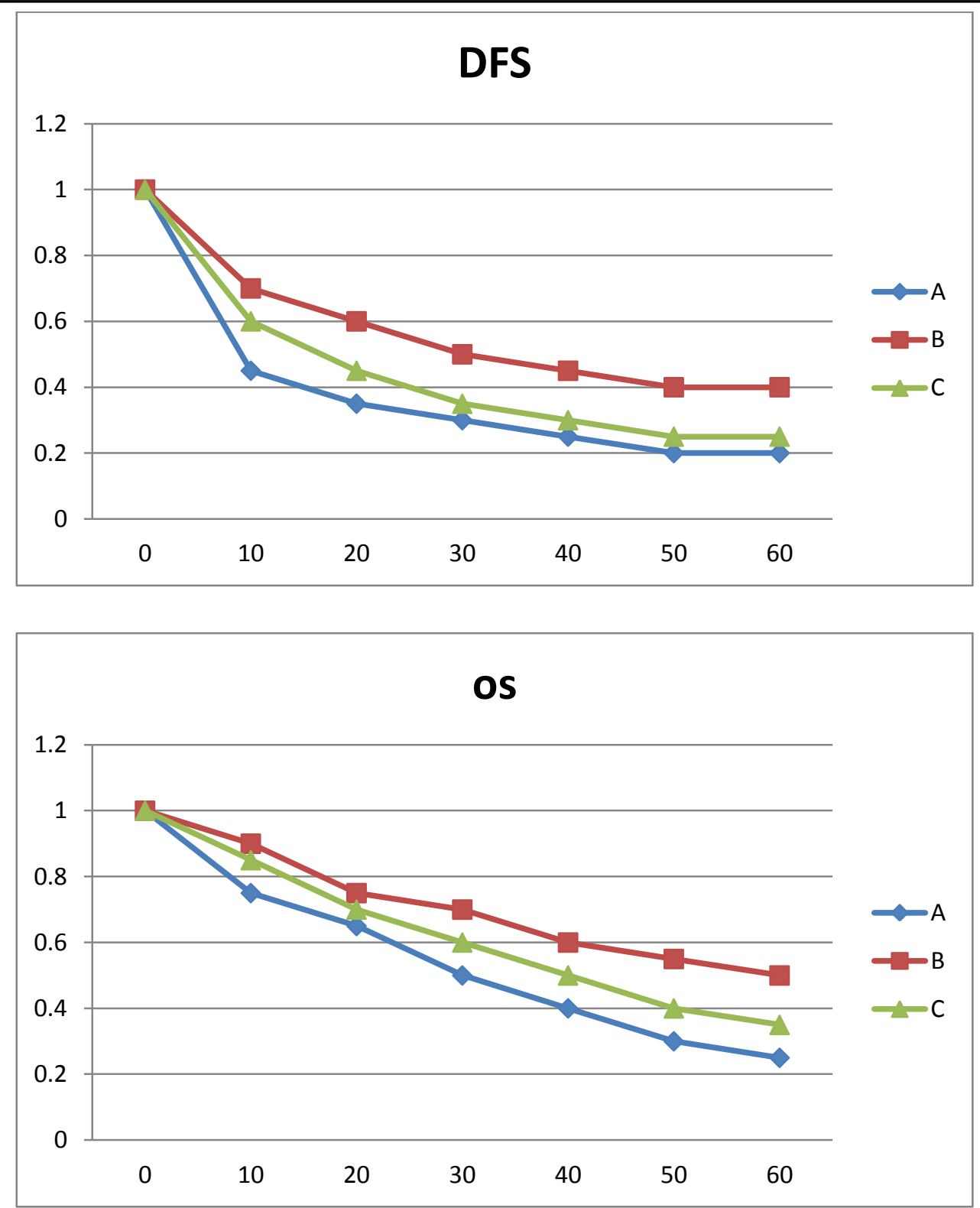

\section{Discussion}

The updated meta analysis of CT in Head and Neck cancer (MACH-NC) confirmed the original findings of $4 \%$ OS withCCRT. ${ }^{6,7,9}$ The study also showed a relative $19 \%$ improvement in survival for concomitant therapy translating into an $8 \%$ absolute benefit in OS with platinum based regimens. However there is confusion regarding the most appropriate CCRT regimen because the data that have been published are very heterogenous regarding the CT drug and its schedule. A randomized trial from Cleveland clinic assigned patients to receive 66 to $72 \mathrm{~Gy} \pm 2$ days of synchronous cisplatin $\left(20 \mathrm{mg} / \mathrm{m}^{2} /\right.$ day $\left.\times 4\right)$ and infusional 5 -FU $\left(1000 \mathrm{mg} / \mathrm{m}^{2} /\right.$ day $\left.\times 4\right)$ during week 1 and 4 of RT. Surgery was planned for patient with residual or recurrent local/nodal disease. Projections for 5 year overall survival with primary site preservation were $34 \%$ Vs $42 \%$ ( $\mathrm{p}=0.004)$ and for local control without surgical resection were $45 \%$ Vs $77 \%(\mathrm{p}<0.001) .{ }^{18}$ In arm C of our study, the 5 year DFS was $25 \%$ vs $20 \%$ in arm A \& 5 year OS was $35 \%$ Vs $25 \%$.In a large single centre experience of weekly cisplatin 30 $\mathrm{mg} / \mathrm{m}^{2}$ concurrently with RT of 70 Gy at 2 Gyperfraction, 5 fractions/week. Gupta et al. reported a 5 year DFS of $43 \%{ }^{19}$. In arm B of our study, the 5 year DFS was $40 \%$ and OS was $50 \%$. Our study used 2 different CT regimens in the CCRT arms and compared their results with an only conventional RT arm. The CR seen at 1 month after completion of treatment was $85 \%$ in 
the weekly cisplatin arm (arm B), 75\% in the 3 weekly cisplatin and 5-FU arm (arm C) and 60\% in the RT only arm (arm A).Acute toxicities were considerably higher in the two CCRT arms as compared to the RT only arm and were similar to the acute radiation morbidity seen in CCRT arm of RTOG 91-11 trial and trial by Forastiere. ${ }^{20}$ Grade III/IV mucositis was significantly higher in arm C (85\%) as compared to arm B (75\%).

Arm A completed the planned treatment without any interruption. In arm B, 15 patients (75\%) completed 6 cycles of the planned weekly chemotherapy, 3 patients $(15 \%)$ received 5 cycles and $2(10 \%)$ received only 4 cycles of weekly chemotherapy. In arm C, all patients (100\%) received at least one cycle of chemotherapy starting from D1 of RT and 15 (75\%) completed the planned 2 courses of the 3 weekly chemotherapy. Chemotherapy in these patients had to be omitted in case of deteriorating performance status, severe mucosal or skin toxicity or neutropenia. Patients in arm B received higher cumulative dose of cisplatin $(90 \%$ receiving atleast $200 \mathrm{mg} / \mathrm{m}^{2}$ ) as compared to arm C $\left(75 \%\right.$ receiving only $160 \mathrm{mg} / \mathrm{m}^{2}$ cisplatin and 8 $\mathrm{gm} / \mathrm{m}^{2} 5$-FU). Higher CR seen in arm B than arm $\mathrm{C}$ may be due to higher chemotherapy dose received by patients in arm $\mathrm{B}$ due to lower toxicity and better compliance as compared to arm $\mathrm{C}$. The overall survival at 5 years was $25 \%$ in arm A, $50 \%$ in arm B and $35 \%$ in arm C which was not statistically significant. DFS at 5 years was $20 \%$ in $\operatorname{arm} \mathrm{A}, 40 \%$ in arm B and $25 \%$ in arm C and the difference was not statistically significant. Treatment interruption in arm B was less than 1 week and was seen in 5 patients. In $\operatorname{arm} \mathrm{C}$, treatment interruption was less than one week in 6 patients and more than one week in 2 patients. More patients were hospitalized for conservative management of acute toxicities in arm $\mathrm{C}$ as compared to arm B (10 patients Vs 7 patients). No patient in arm A was hospitalized for toxicity management. The incidence of late toxicities like xerostomia and subcutaneous fibrosis were almost similar in the three arms. This was as expected because these toxicities depend on radiation dose which was similar in the 3 arms. Hearing loss was seen only in the CCRT arms probably due to the ototoxic effect of cisplatin.

\section{Conclusion}

In this study the OS and DFS at 5 years is superior in the arm receiving weekly cisplatin as compared to the arm receiving 3 weekly cisplatin based regime \& RT only arm. However, the difference in overall survival and disease free survival between the three arms was found to be not statistically significant; the number of patients in each arm were only 20. Use of prospective randomized trial is warranted in this setting. The weekly cisplatin based CCRT is a tolerable and effective regimen for treating locally advanced squamous cell carcinoma of head \& neck region. The limitation of this study is that it is a retrospective study.

\section{Acknowledgement}

We would like to thank our patients and the staff of Dept. of Radiotherapy for their support in completing this study.

\section{References}

1. Halperin, E.C., Perez C.A. et al. Principles and Practices of Radiation Oncoloy. 2013; (6): 718.

2. Kulkarni, M.R. Head and Neck Cancer burden in Indian. Internatioanl Journal of Head and Neck Surgery 20134(1): 29-35.

3. Forastiere A, Koch W, Ttotti A, Sidransky D: Medical progress - Head and Neck cancer. N Eng J Med. 2001, 345: 1890 1900, 10: 1056/NEJM ra 001375

4. Chin D, Boyle GM, Porceddu S, Theile DR, Parsons PG, ComanWB : Head and Neck cancer - Past Present and Future. Expert Rev Anticancer Ther. 2006, :11111118

5. Pignon JP, Bourhis J, Domenge $\mathrm{C}$, Designe L: Chemotherapy added to locoregional treatment for head and neck 
squamous - cell carcinoma: three meta analyses of updated individual data. Lancet. 2000, 355: 949-955

6. Pignon JP, le Maitre A, Bourhis J, MACHNC Collaborative group: Meta - analyses of Chemotherapy in Head and Neck Cancer ( MACH - NC). Int J Radiat Oncol Phys. 2007, 69 (2 suppl): S112 -114

7. Pignon JP, Baujat B, Bourhis J: Individual patient data meta - analyses in head and neck carcinoma: What have we learnt? Cancer Radiother. 2005, 9: 31-36.

8. Salama J.K., Seiwert T.Y., Vokes E.E. Chemoradiotherapy for locally advanced head and neck cancer. J. Clin Oncol. 2007; 25: 4118-26.

9. Pignon J.P., Le Maitre A., Maillard E., Bourhis J. MACH-NC collaborative group. Meta analysis of chemotherapy in head and neck cancer (MACH-NC) an update on 93 randomised trials and 17,346 patietns. Radiother. Oncol. 2009; 92(1): 414.

10. Adelstein Dj, Li Y, Adams G.L., Wagner H., Jr. Kush J.A. Ensley J.F. et al., An intergroup phase III comparison of standard radiation therapy and two scheules of concurrent chemoradiontherapy in patients with unrsectable squamous cell had nad neck cancer. J. Clin Oncol. 2003; 231: 92-8.

11. Bernier J, Domenge C, Ozsahin M et al.Postoperative irradiation with or without concomitant chemotherapy for locally advanced head and neck cancer. N Engl J Med. 2004;350(19):1945-1952.

12. Cooper J S, Pajak T F, Forastiere A A et al.Postoperative concurrent radiotherapy and chemotherapy for high-risk squamouscell carcinoma of the head and neck. N Engl J Med. 2004;350(19):1937-1944.

13. Fountzilas G, Skarlos D, Kosmidis P et al. Radiation therapy and concurrent cisplatin administration in locally advanced head and neck cancer. A Hellenic Co-operative
Oncology Group study. Acta

Oncol. 1994;33(07):825-830.

14. Bloom E.J., Green M.D. et al. Concomitant use of cisplatin and radiotherapy in the treatment of advanced head and neck cacner, Oncology, 1985; 4: 137.

15. Tribius S, Kronemann S, Kilic Y., Schroder U. et al., Radiochemotherapy including cisplatin alone versus cisplatin + $5 \mathrm{FU}$ for locally advanced unresectable stage IV squamous cell carcinoma of the head and neck. Strahlenther Oncol. 2009; 185(10): 675-81.

16. Uygun K., Bilci A., Karogol H. et al. The comparison of weekly and thrice weekly cisplatin chemotherapy concurrent with radiotherapy in patients with previously untreated in operable non-metastatic squamous cell $\mathrm{CA}$ of $\mathrm{H} \& \mathrm{~N}$ Cancer, Chothe. Pharmacol. 2009: 64(3) 601-5.

17. Wendt T.G., Grabenbauer GG, Rodel CM, Thiel HJ, Aydinh, Rohloff R, et al. Simultaneous radiochemotherapy versus radiotherapy alone in advanced head and neck cancer. A randomized multicenter study. J. Clin. Oncol 1998; 16: 1318-24.

18. Adelstein D.J., Lavertu P., Saxton J.P. Secec M, Wood B.G., Wanamaker J.R., Eliachar I, Strome M, Lato M.A. Mature results of a phase III randomised trial comparing concurrent chemoradiotherapy with radiation therapy alone in patients with stage III and IV squamous cell carcinoma of the Head \& Neck Cancer, 2000; Feb. 2015; 88(4): 876-83.

19. Gupta T., Agarwal J.P., Ghosh Laskar, S., Parikh, P.M. D'Cruz, A.K., Dinshaw, K.A. Radical radiotherapy with concurrent weekly cisplatin in locoregionally advanced squamous cell carcinoma of the head and neck : a single institution experience, Head Neck Oncol. 2009; 1:

20. Forastiere AA,Long-term results of RTOG 91-11: a comparison of three nonsurgical 
treatment strategies to preserve the larynx in patients with locally advanced larynx cancer. J Clin Oncol. 2013 Mar 1;31(7): 845-52. doi: 10.1200/JCO.2012.43.6097. Epub 2012 Nov 26. 